\title{
The Effects of Acute Ingestion of a High-fat Solution, Compared to a High-Carbohydrate Solution, on Skeletal Muscle Oxygenation, Fat Oxidation and Performance During a 2-hour Cycling Effort Followed by a Short Time Trial in Cyclists and Triathletes
}

\author{
Antoine Jolicoeur Desroches ${ }^{1,2}$, Frédéric Domingue ${ }^{1,2}$, Louis Laurencelle ${ }^{1}$, Claude Lajoie ${ }^{1,2}$ \\ ${ }^{1}$ Université du Québec à Trois-Rivières, Québec, Canada \\ ${ }^{2}$ L-Tips laboratory, Université du Québec à Trois-Rivières, Québec, Canada
}

\begin{abstract}
This study aimed to determine the effects of consuming a high fat solution (HFS) compared to a high carbohydrate solution (HCS) during a cycling effort on substrate oxidation, muscle oxygenation and performance with cyclists and triathletes. Thirteen men participated in this study (age: $30.4 \pm 6.3 \mathrm{y}$; height: $178.7 \pm 6.1 \mathrm{~cm}$; weight: $74.9 \pm 6.5 \mathrm{~kg}$; $\dot{\mathrm{VO}}{ }_{2}$ peak: $60.5 \pm 7.9 \mathrm{mlO} \cdot \mathrm{kg}^{-1} \cdot \mathrm{min}^{-1}$ ). The solutions were isocaloric (total of $720 \mathrm{kcal}$ ) and were consumed every 20 minutes. Each solution of HFS contained $12.78 \mathrm{~g}$ of lipids, $1.33 \mathrm{~g}$ of carbohydrates and $0.67 \mathrm{~g}$ of proteins, and each solution of HCS contained $28 \mathrm{~g}$ of carbohydrates. We measured pulmonary oxygen consumption and skeletal muscle oxygenation, using a Near Infrared Spectrometer (NIRS) during a cycling effort consisting of 2 hours at $65 \%$ of maximal aerobic power (MAP) followed immediately by a 3-minute time-trial (TT). We observed that the consumption of the HFS increased the rate of fat oxidation at the end of the sub-maximal effort $(0.61 \pm 0.14$ vs $0.53 \pm$ $0.17 \mathrm{~g} \cdot \mathrm{min}^{-1}, p<0.05$ ). We have also shown that the HFS negatively affected the performance in the TT (mean Watts: HCS: $347.0 \pm 77.4$ vs HFS: $326.5 \pm 88.8 \mathrm{~W} ; p<0.05)$ and the rating of perceived exertions during the sub-maximal effort (modified Borg Perceived Exertion scale: $1-10$ ) (mean: $3.62 \pm 0.58$ for HCS vs $4.16 \pm 0.62$ for HFS; $p<$ 0.05 ). We did not observe a significant effect of the acute consumption of the HFS compared to the HCS on muscle oxygenation during the cycling effort. Finally, we observed that cyclists who demonstrated a high skeletal muscle deoxygenation relative to their pulmonary oxygen consumption $\left(\Delta \mathrm{HHb} / \mathrm{V}_{2}\right)$ had a higher fat oxidation capacity (higher Fat ${ }_{\max }$ ). In conclusion, even though the consumption of HFS increased the rate of fat oxidation at the end of a sub-maximal effort, it did not affect muscle oxygenation and it negatively affected performance and perceived exertion during a time-trial and caused gastro-intestinal distress in some participants.
\end{abstract}

Keywords: fat oxidation, skeletal muscle oxygenation, lipid supplementation, carbohydrate supplementation, Near Infrared Spectroscopy (NIRS), cycling, triathlon.

\section{INTRODUCTION}

\section{Background}

Long distance triathlons and cycling competitions are gaining in popularity (Hadzipetros, 2009; Smale, 2016) and athletes are looking for ways to improve their performance, whether it is with a better-structured training plan, better equipment or by improving their nutrition. Due to the duration and intensity of these events, fueling properly is a big challenge for the athletes. Even though it is known 
that carbohydrate is the ideal fuel for endurance events and high intensity exercise (Burke, 2010), it is interesting for an endurance athlete to increase their ability to oxidize lipids since the quantity of lipids in adipose tissue and in the muscles is considerably larger than the quantity of glycogen in the liver and the muscles (Gonzalez et al., 2016; Jensen et al., 2011; Maunder et al., 2018). A good fat oxidation capacity, combined with carbohydrate intake during endurance events, would allow an athlete to preserve more glycogen which can be used when the intensity increases, such as when a cyclist needs to respond to an acceleration or at the end of the race when the athletes are accelerating toward the finish line (Hall et al., 2016; Jeukendrup \& Achten, 2001). Frandsen et al. (2017) found that the maximal fat oxidation of triathletes competing in an Ironman triathlon is related to their performance in this ultra-endurance event. Endurance athletes generally have a good fat oxidation capacity, but there are many ways an athlete can increase even more their fat oxidation capacity, such as doing long aerobic training, doing fasted training, training twice a day or by training with minimum or without carbohydrate intake (Hawley, 2014).

Consuming lipids during exercise will increase acutely the rate of oxidation of fat, which can be determined by measuring the volume of oxygen and carbon dioxide consumed during the exercise and by using stoichiometric equations. However, it is not known if the effect of the acute ingestion of a HFS during exercise can be observed directly in the muscles by measuring deoxygenation $(\mathrm{HHb})$ in the muscles, using Near Infrared Spectroscopy (NIRS). It is known that to regenerate ATP, more oxygen is needed when fat is oxidized compared to when glucose is oxidized (Burke et al., 2017; Jeukendrup \& Wallis, 2004; Welch et al., 2007), so it is expected that acute fat ingestion will have an effect on muscle oxygenation. Since the main focus of the study is on muscle oxygenation, this study will explore the acute effect of fat ingestion during exercise rather than exploring the chronic effects of consuming lipids.

NIRS has been used by many to measure the blood influx and muscle oxygenation during exercise (Bhambani, 2004, Boone et al., 2010, Bringard \& Perrey, 2004). The study from Zurbuchen et al. (2020) is the first study to demonstrate an association between the fat oxidation kinetics in the whole body and the muscle deoxygenation in the muscles in individuals of different fitness levels. Endurance training is associated with many adaptations such as enhanced oxidative enzyme activity, enhanced mitochondrial activity and increased mitochondrial volume and density (Baum et al., 2015; Bloor, 2005; Helge et al., 2007; Zuburchen et al., 2020). These adaptations are associated with both fat oxidation capacity and muscle oxygenation. Indeed, the increase in the capillarization improves muscle oxygenation and enhances the surface area of exchange of substrates and the entry of fatty acids in the muscle cells, which results in a better fat oxidation capacity (Hawley et al., 2014; Sahlin et al., 2008).

Therefore, since fat oxidation is related to muscle oxygenation, it is possible that the change in the rate of oxidation produced by the ingestion of a high fat solution could be measured directly in the muscle using NIRS. To our knowledge, it has not been studied. Therefore, the objective of this study was to determine the effects of consuming a high fat solution compared to a high carbohydrate solution (HCS) during a cycling effort on the oxidation of energetic substrates, on muscle oxygenation and on performance with cyclists and triathletes.

We hypothesized that the deoxyhemoglobin $(\mathrm{HHb})$ would be higher when the participants consume the high fat solution since more oxygen would be used in the muscles, due to a higher fat oxidation rate. We also hypothesized that the fat oxidation would be higher when the subjects are consuming a HFS compared to a HCS. Furthermore, we believed that the rate of perceived exertion (RPE) would be significantly higher when the participants consume the HFS compared to the HCS since it has been demonstrated that ingesting carbohydrates during exercise lowers the RPE (Coggan \& Coyle, 1987; Kang et al., 1996; Robertson et al., 1990; Utter et al., 2002; Utter et al., 2004). Also, we supposed that the performance during the time-trial would be negatively affected when the participants consume the HFS.

\section{METHODS}

\section{Participants}

Study participants were limited to male cyclists and triathletes who competed in triathlon or cycling competitions for at least two years and who regularly train for at least 10 hours per week. Furthermore, participants were required to be between 18 and 40 years old. Participants with 
diabetes and/or other medical problems as well as participants with nut allergies were excluded from this study. Furthermore, participants who followed a low carbohydrate-high fat diet (LCHF) were also excluded. Fifteen individuals participated in the study, but 13 participants completed the study (age: $30.4 \pm 6.3 \mathrm{y}$; height: $178.7 \pm 6.1 \mathrm{~cm}$; weight: $74.9 \pm 6.5 \mathrm{~kg} ; \mathrm{VO}_{2}$ peak: $\left.60.5 \pm 7.9 \mathrm{mlO}_{2} \cdot \mathrm{kg}^{-1} \cdot \mathrm{min}^{-1}\right)$. The participants were recruited via a publication on the Facebook page of the L-Tips lab and on the main scientist's Facebook page. The inclusion and exclusion criteria were mentioned on the publication, and the scientist contacted the people interested via e-mail to make sure they met the criteria.

\section{Ethics Statement}

This study was approved by the Ethics Committee at the Université du Québec à Trois-Rivières (CER-20-268-07.01) and was in accordance with the Helsinski declaration of 1975, as revised in 2000. Voluntary, written, informed consent was given by all participants. Study data was deidentified and anonymized to maintain anonymity.

\section{Methodology}

The study followed a single blind, randomized cross-over design. Each participant completed three sessions. The first session was a preliminary test to determine the metabolic and physiological values of the participants and was used to allow the participants to familiarize themselves with the equipment. The interval of time between each session varied between 5 and 10 days. A minimum of 5 days was necessary to make sure that the participants fully recovered from the previous experimentations. The participants were instructed to refrain from doing any intense and/or long training in the 48 hours before each experimentation. The participants were also instructed to eat the same meals and to consume the same amount of caffeine (if the participant regularly consumes caffeine) before each experimentation.

In the first session, the height and body weight of the participants were measured. The body weight was also measured for the following two sessions. Before each session, a near-infrared spectrometer (Portamon, Artinis Medical Systems BV, Utrecht) was installed on the right vastus lateralis of the participants at $40 \%$ of the distance between the patella and the greater trochanter (measured from the patella) and this area was shaved. The device was placed on the vastus lateralis because this muscle is active during cycling and since many studies have used the vastus lateralis for muscle oxygenation measurements (Gendron et al., 2018; Jeffries et al., 2019; Murias et al., 2011; Murias et al., 2013). Then, the spectrometer was placed in a clear plastic bag to prevent sweat being in contact with the device. Furthermore, a black cloth was placed over the device in order to prevent contamination by the ambient light and an elastic bandage wrap was used to make sure the device did not move during the experimentation. The cycling short of the participant was then placed over the bandage wrap to prevent movement of the device and to protect it even more from light contamination.

Near infrared spectroscopy (NIRS) allows the non-invasive measurement of muscle oxygenation and blood influx in the muscle (Binzoni et al., 1999; Ferrari et al., 2016; Grassi et al., 2003; Ryan et al., 2012). The light in the near-infrared (NIR) region $(\sim 700-900 \mathrm{~nm})$ is able to penetrate into biological tissues. The light absorption properties of hemoglobin and myoglobin vary, depending on whether they are bound to oxygen or not (Barstow, 2019). NIRS measures the quantity of oxyhemoglobin $\left(\mathrm{HbO}_{2}\right)$, deoxyhemoglobin $(\mathrm{HHb})$, total hemoglobin $(\mathrm{THb})$ as well as the tissue saturation index (TSI \%) (Barstow, 2019).

A calibration protocol was executed before every experimentation to determine the participants' muscle oxygenation values at rest and during occlusion (Ryan et al., 2012). The participants were lying down on a massage table and were asked to remain lying down and relaxed for a period of 5 minutes in order to measure their baseline values. During that time, they were asked to keep their legs as relaxed as possible and to refrain from talking. After the 5-minute rest period, a blood flow restriction cuff (The occlusion cuff elite ${ }^{\circledR}$ ) was inflated at pressure of $300 \mathrm{mmHg}$ with an air compressor (Ryan et al., 2012). The pressure was maintained for a 5-minute period by micro-adjusting the air flow with a valve. This occlusion period is used to determine the minimum oxyhemoglobin and total hemoglobin values as well as the maximum deoxyhemoglobin values. After the occlusion period, the cuff was deflated and was removed from the leg. The participant remained lying down for a period of three minutes, in order to measure the hyperemic response.

$\Delta \mathrm{HHb}, \Delta \mathrm{THb}$ and $\Delta \mathrm{Hbdiff}$ were measured by subtracting the value at each moment by the baseline value measured at rest (Gendron et al., 2018; Jeffries et al., 2019; Murias et al., 2013): 


\section{$\Delta \mathrm{HHb}(t)=\mathrm{HHb}(t)-\mathrm{HHB}($ baseline $)$}

Furthermore, $\% \mathrm{HHb}$ at a specific time was measured using this formula (Celi et al., 2012; Fadel et al., 2004):

$\% \mathrm{HHb}(t)=\frac{H H b(t)-H H b(\text { baseline })}{H H b(\text { occlusion })-H H b(\text { baseline })} \times 100 \%$.

$(t)=$ time $(\mathrm{sec})$

The ratio between the deoxygenation in the vastus lateralis $(\triangle \mathrm{HHb})$ and the systemic oxygen consumption $\left(\dot{\mathrm{V}}_{2}\right) \quad\left(\Delta \mathrm{HHb} / \dot{\mathrm{V}} \mathrm{O}_{2}\right)$ was also calculated. At a constant sub-maximal intensity, a lower $\Delta \mathrm{HHb} / \dot{\mathrm{V}}_{2}$ ratio determines enhanced local muscle blood flow distribution, whereas a higher ratio determines decreased microvascular blood flow and a higher reliance on muscle deoxygenation (Mitchell, 2017; Murias et al., 2011; Spencer et al., 2012). Furthermore, $\Delta \mathrm{HHb} / \dot{\mathrm{VO}}_{2}$ kinetics during an incremental test can demonstrate whether $\mathrm{O}_{2}$ extraction in the muscle increases or plateaus at high intensity as systemic oxygen consumption increases. A constant increase of $\Delta \mathrm{HHb} / \dot{\mathrm{VO}}_{2}$ up to exhaustion during an incremental test was observed in elite athletes (Gendron et al., 2018).

$\mathrm{HHb}$ increases linearly during an incremental test and towards the end of the test, the increase in $\mathrm{HHb}$ plateaus slightly. The moment when $\mathrm{HHb}$ begins to plateau is named the breaking point $\left([\mathrm{HHb}]_{\mathrm{bp}}\right)$. The $\mathrm{HHb}$ breaking point during the maximal incremental test was determined by plotting the $\mathrm{HHb}$ values against the $\%$ of $\dot{\mathrm{V}}_{2}$ peak in order to determine visually at what intensity the breaking point occurs (Ianetta et al., 2017; Zurbuchen et al., 2020).

In addition to the muscle oxygenation measured with NIRS, oxygen consumption was measured with a metabolic analyzer (MOXUS, AEI, USA) during all the experimentations. The metabolic analyzer was calibrated before each experimentation with 2 gas of known concentrations. The injection volume was calibrated with a $3000 \mathrm{~mL}$ calibration syringe (Hans Rudolph 5530 series). Furthermore, the RPE was noted throughout all the experimentations. For the first experimentation, the RPE was noted at the middle of each ladder of the incremental test with a modified Borg scale (1 to 10) and for the following two experimentations; it was noted every ten minutes. The heart rate (Garmin, Olathe, USA) was also continuously measured during all the experimentations. The gastrointestinal distress or discomfort during the experimentations was assessed every 10 minutes using a scale ranging from "No discomfort" to "Small discomfort" to "GI distress".

For the first session, the participants arrived at the laboratory in the morning in a fasted state (overnight fast), since it is recommended to perform the Fat ${ }_{\max }$ test in a fasted state (Achten et al., 2002; Maunder et al., 2018). They were allowed to consume coffee (black coffee without sugar or milk) in the morning but not in the two hours preceding the test, and to drink water. The participants performed a maximal incremental test on a cycle ergometer. The participants used their own bicycles, which were installed on a Tacx NEO 2 smart trainer (Tacx, Wassenaar, Netherlands). Before the beginning of the test the heart rate and oxygen consumption values were measured for a 3-minute period, while the participants remained seated on their bicycle. The test began at an intensity of 100 watts and the intensity increased by 30 watts every 3 minutes. The participants were asked to remain seated on their saddle throughout the test and to maintain a constant pedaling frequency between 80 and $110 \mathrm{rpm}$. The test stopped when the participant stopped due to exhaustion or if the participant could not maintain a pedaling frequency superior to $60 \mathrm{rpm}$ despite being encouraged to increase the pedaling frequency. The $\dot{\mathrm{V}}{ }_{2}$ peak was determined by averaging the peak $\dot{\mathrm{VO}}_{2}$ for 30 seconds. The maximal aerobic power (MAP) was determined as the intensity (watts) corresponding to the $\mathrm{V}_{2}$ peak. If a power ladder was not fully completed, 5 watts were added to the previous ladder completed for every 30 seconds completed. The maximal fat oxidation (MFO) was determined as the highest absolute rate of fat oxidation $\left(\mathrm{g} \cdot \mathrm{min}^{-1}\right)$ during the incremental test and the Fat max $_{\text {ax }}$ was determined as the intensity corresponding to the MFO (Achten et al., 2002; Nordby et al., 2006).

After the preliminary experimentation, following a single blind, randomized crossover design, the participants completed two experimentations at an interval of 7 to 10 days between each experimentation. Taking into account diurnal variations in measurements of oxygen consumption, the two experimentations occurred at the same time of day for every participant (Knaier et al., 2019). The order of the experimentations was determined randomly using Microsoft Excel. The participants were also instructed to eat the same meals and at the same time of day and to consume the same amount of caffeine (if the participant regularly consumes caffeine) before each experimentation, but to refrain from caffeine in the two hours preceding 
the experimentations. For the two experimentations, the participants cycled for two hours at an intensity corresponding to $65 \%$ of the MAP (SE: steady effort) and then immediately executed a 3-minute time trial (TT). An intensity of $65 \%$ of the MAP was used because it approximates the intensity of an Ironman triathlon or a long-distance cycling race (Noakes, 2001; Stebbins et al., 2014).

During the SE the intensity was set on the cycle ergometer using the Ergo mode so the participants did not have to change gears, and for the TT the cycle ergometer was set on the Slope mode, at a $1 \%$ gradient, and the participants could change their gearing to adjust the intensity of the trainer. For the experimentations, the participants consumed either $28 \mathrm{~g}$ of carbohydrates (HCS) or $12.78 \mathrm{~g}$ of lipids, $1.33 \mathrm{~g}$ of carbohydrates and $0.67 \mathrm{~g}$ of proteins (HFS) every 20 minutes, starting at the $10^{\text {th }}$ minute of the effort, for a total of $720 \mathrm{kcal}$, and the participants were instructed to consume water ad libidum. The quantity of the substrate was determined based on the nutrition recommendations of consuming between 60 and 90 grams of carbohydrates per hour during exercise of length superior or equal to 2 hours (Burke \& Hawley, 2018; Stellingwerff \& Cox, 2014). The HCS used was Hammer gel chocolate (Rocky Mountains, Montana, USA) and it consisted of a mix of different carbohydrates: maltodextrin, tapioca syrup, grape juice, rice dextrin and cultured dextrose. The high fat solution (HFS) was a mix of two $F$ bomb nut gels (Burlington, North Carolina, USA) with $35 \mathrm{ml}$ of medium chain triglycerides (MCT) oil, which was divided equally into 6 flasks. The $F$ Bomb gel is made from macadamia nuts and dark chocolate. We used mix of the nut gel and the MCT oil since the ingestion of a considerable quantity of MCT oil can cause GI distress (Gomes \& Aoki, 2014; Ivy et al., 1980; Lowery, 2004). The MCT oil consists of medium chain fatty acids (MCFAs) and they do not require the transporter CPT-1 to be transported into the mitochondria, contrary to the long chain fatty acids (LCFAs) in the macadamia nut gel (Achten \& Jeukendrup, 2004; Jeukendrup \& Aldred, 2004; Lowery, 2004; Rengel et al., 2015). Therefore, MCFAs can be oxidized faster and at a higher intensity compared to LCFAs (Massicotte et al., 1992). The flavor of both the HCS and the HFS was chocolate, and the flasks were opaques so the participants could not look at the texture or the color of the solutions. However, due to the taste and texture of macadamia nuts in the HFS, the HFS was easily identifiable.

\section{Laboratory Test Protocols and Measurements}

$\dot{\mathrm{V}} \mathrm{O}_{2}$ and $\dot{\mathrm{V}} \mathrm{CO}_{2}$ were measured throughout the graded incremental test. During the following two experimentations, $\dot{\mathrm{V}} \mathrm{O}_{2}$ and $\dot{\mathrm{V}} \mathrm{CO}_{2}$ were measured during the first 10 minutes then they were measured every 20 minutes for a duration of 5 minutes. Fat and $\mathrm{CHO}$ oxidations were calculated using the following stoichiometric equations, which take into account that the urinary nitrogen excretion is negligible (Achten \& Jeukendrup, 2003; Bossi et al., 2019; Péronnet \& Massicotte, 1991):

$$
\begin{aligned}
& \text { Fat oxidation }(\mathrm{g} / \mathrm{min})=1.67 \times \dot{\mathrm{V}} \mathrm{O}_{2}-1.67 \times \dot{\mathrm{VCO}}_{2} \\
& \mathrm{CHO} \text { oxidation }(\mathrm{g} / \mathrm{min})=4.55 \times \dot{\mathrm{V} C \mathrm{CO}_{2}-} \\
& 3.21 \times \dot{\mathrm{V}} \mathrm{O}_{2} \\
& \mathrm{EE}(\mathrm{J} / \mathrm{s})=281.67 \times \dot{\mathrm{V}} \mathrm{O}_{2}+80.65 \times \dot{\mathrm{V}} \mathrm{CO}_{2}
\end{aligned}
$$

The fat and carbohydrate oxidations were not calculated during the 3-minute time-trial since it has been observed that at an intensity superior to $75 \%$ of $\dot{\mathrm{VO}}_{2} \max$, the stoichiometric equations are not valid (Jeukendrup \& Wallis, 2005; Romijn et al., 1992).

Furthermore, gross efficiency (GE) during the two experimentations was measured using the following formula (Bossi et al., 2019):

GE $(\%)=\left[\right.$ mechanical power output $\left(\mathrm{J} \cdot \mathrm{s}^{-1}\right) /$ metabolic power input $\left.\left(\mathrm{J} \cdot \mathrm{s}^{-1}\right)\right] \times 100$

The GE measures the relationship between the mechanical power output that is generated by the participants with the metabolic power input that is required to generate that quantity of power. This measure is significant for endurance athletes since a better GE means that less energy is required to generate a specific quantity of power (Coyle, 1995; Coyle, 2005; Hopker et al., 2009; Horowitz et al., 1994; Jeukendrup et al., 2000).

\section{Statistical Analyses}

Paired $t$ tests were performed to assess the systematic variance between the HCS and the HFS experimentations for sets of specific values, such as the performance in the 3-minute time trial, the metabolic values and the muscle oxygenation values. A regression analysis was performed to determine if there was a significant correlation between the $\dot{\mathrm{V}} \mathrm{O}_{2}$ peak and different values such as the Fat ${ }_{\max }$ intensity, the maximal fat oxidation (MFO) and the $[\mathrm{HHb}]$ breaking point. Also, 
an analysis of variance was used to determine whether there was a significant shift of both \% $\dot{\mathrm{V}} \mathrm{O}_{2}$ peak, percentage of energy expenditure from fat oxidation and the respiratory exchange ratio (RER) during the 2-hour effort. Furthermore, the order of effect was calculated. Statistics, tables and figures were analyzed and created with Microsoft Excel 2020. Data in the tables are presented as means \pm SD (standard deviation), whereas data in the figures are presented as means \pm SEM (standard error of mean). Statistical significance was set as $p \leq 0.05$.

\section{RESULTS}

\section{Participants characteristics}

Fifteen male cyclists and triathletes participated in this study (14 triathletes, 1 cyclist). The characteristics of the participants are presented in Table 1. One participant only completed the preliminary test and did not complete the first experimentation due to an injury, and one participant did not complete the two experimentations due to gastrointestinal distress caused by the consumption of the HFS and because he was not able to sustain the required effort for the remaining 30 minutes. Therefore, thirteen participants completed the study (12 triathletes, 1 cyclist).

Table 1. Mean descriptive data of study participants

\begin{tabular}{|c|c|}
\hline Variables & \\
\hline Age (years) & $30.4 \pm 6.3$ \\
\hline Height $(\mathrm{cm})$ & $178.7 \pm 6.1$ \\
\hline Weight $(\mathrm{kg})$ & $74.9 \pm 6.5$ \\
\hline$\dot{\mathrm{VO}}_{2}$ peak $\left(\mathrm{mlO}_{2} \cdot \mathrm{kg}^{-1} \cdot \mathrm{min}^{-1}\right)$ & $60.5 \pm 7.9$ \\
\hline $\mathrm{MAP}(\mathrm{watts})$ & $337.2 \pm 60.7$ \\
\hline $\mathrm{MAP}\left(\mathrm{w} \cdot \mathrm{kg}^{-1}\right)$ & $4.5 \pm 0.7$ \\
\hline
\end{tabular}

MAP: maximal aerobic power; $\dot{\mathrm{VO}}_{2}$ peak: peak oxygen consumption. $\mathrm{N}=13$

The fat oxidation and muscle oxygenation values from the preliminary test are shown in table 5-2. The mean $\dot{\mathrm{VO}}_{2}$ peak was $60.5 \pm 7.9 \mathrm{mlO}_{2}$. $\mathrm{kg}^{-1} \cdot \mathrm{min}^{-1}\left(48.33 \quad-\quad 76.03 \quad \mathrm{mlO}_{2} \cdot \mathrm{kg}^{-1} \cdot \mathrm{min}^{-1}\right)$ and the mean maximal aerobic power (MAP) was $337.2 \pm 60.7 \mathrm{~W}$. The mean $\mathrm{Fat}_{\max }$ intensity in watts was $148.5 \pm 74.0 \mathrm{~W}$ and the mean relative $\mathrm{Fat}_{\max }$ intensity presented as a percentage of the $\dot{\mathrm{V}}_{2}$ peak was $51.1 \pm 12.0 \%$. The mean maximal fat oxidation was $0.74 \pm 0.26 \mathrm{~g} \cdot \mathrm{min}^{-1}$. We observed a significant positive correlation between the $\mathrm{V}_{2}$ peak of the participants and the Fat ${ }_{\text {max }}$ intensity $(\mathrm{r}=0.53 ; p<$ $0.05)$. However, we did not observe a significant correlation between the $\mathrm{V}_{2}$ peak and the maximal fat oxidation $(r=0.27)$. Furthermore, we did not obtain a significant correlation between the $\dot{\mathrm{VO}}_{2}$ peak and the relative MFO $\left(\mathrm{mg} \cdot \mathrm{min}^{-1} \cdot \mathrm{kg}^{-1}\right)(\mathrm{r}=0.29$; $p=0.29$ ).

We observed a deoxyhemoglobin ( $\mathrm{HHb}$ ) breaking point $\left([\mathrm{HHb}]_{\mathrm{BP}}\right)$ in 10 of the 13 participants. For the other three participants, $\triangle \mathrm{HHb}$ increased linearly during the test up to $\mathrm{VO}_{2}$ peak. The mean $[\mathrm{HHb}]_{\mathrm{BP}}$ for the 10 participants was $74.9 \pm 12.2 \%$ $\mathrm{VO}_{2}$ peak. The muscular deoxygenation relative to the pulmonary oxygen consumption $(\Delta \mathrm{HHb} /$ $\dot{\mathrm{V}} \mathrm{O}_{2}$ ) was also calculated during the incremental test. For 11 out of the 13 participants, $\Delta \mathrm{HHb} / \dot{\mathrm{VO}}_{2}$ increased as the intensity increased until reaching a maximum value and it then decreased. However, for two participants, $\Delta \mathrm{HHb} / \mathrm{V}_{2}$ increased until $\dot{\mathrm{V}} \mathrm{O}_{2}$ peak. We observed a correlation between the Fat $\max _{\max }$ intensity $\left(\% \mathrm{VO}_{2}\right.$ peak $)$ and the intensity corresponding to the max $\Delta \mathrm{HHb} / \dot{\mathrm{VO}}_{2}\left(\% \dot{\mathrm{VO}}_{2}\right.$ peak $)$ $(\mathrm{r}=0.696 ; p=0.004)$.

Table 2. Fat oxidation and muscle oxygenation values from preliminary tests

\begin{tabular}{|c|c|}
\hline Fatmax (Watts) & $148.5 \pm 74.0$ \\
\hline Fatmax (\%)O 2 peak) & $51.1 \pm 12.0$ \\
\hline Maximal fat oxidation $\left(\mathrm{g} \cdot \mathrm{min}^{-1}\right)$ & $0.74 \pm 0.26$ \\
\hline $\begin{array}{l}\text { Relative maximal fat oxidation } \\
\left(\mathrm{mg} \cdot \mathrm{min}^{-1} \cdot \mathrm{kg}^{-1}\right)\end{array}$ & $9.9 \pm 3.4$ \\
\hline$[\mathrm{HHb}] \mathrm{BP} *\left(\% \dot{\mathrm{VO}}_{2}\right.$ peak $)$ & $74.9 \pm 12.2$ \\
\hline $\max \Delta \mathrm{HHb} / \dot{\mathrm{V}} \mathrm{O}_{2}$ intensity $\left(\% \dot{\mathrm{V}} \mathrm{O}_{2}\right.$ peak $)$ & $73.8 \pm 15.7$ \\
\hline
\end{tabular}

$\mathrm{HHb}$ : deoxyhemoglobin, $[\mathrm{HHb}]_{\mathrm{BP}}$ deoxyhemoglobin breaking point; $\mathrm{VO}_{2}$ peak: peak oxygen consumption.

$\mathrm{N}=13$

$* \mathrm{~N}=10$

\section{Metabolic measurements during the cycling efforts}

\section{$2 \mathrm{~h}$ at $65 \%$ MAP}

Mean oxygen consumption was slightly higher during the SE when the participants consumed the HCS compared to the HFS, but the difference was not significant $\left(41.5 \pm 6.0 \mathrm{vs} 40.9 \pm 5.01 \mathrm{mlO}_{2} \cdot \mathrm{kg}^{-1} \cdot \mathrm{min}^{-1}\right)$. As shown in fig. 1. (A-B), oxygen consumption and the heart rate drifted during the SE for both HCS and HFS $(p<0,001)$. Furthermore, the analysis of variance showed that the RER slope for both the HCS 
Figure 1. (A), Percentage of maximal oxygen consumption, (B), heart rate, (C) RER and (D), percentage of energy expenditure from fat oxidation during the $2 \mathrm{~h}$ at $65 \%$ of MAP when consuming either carbohydrates or lipids

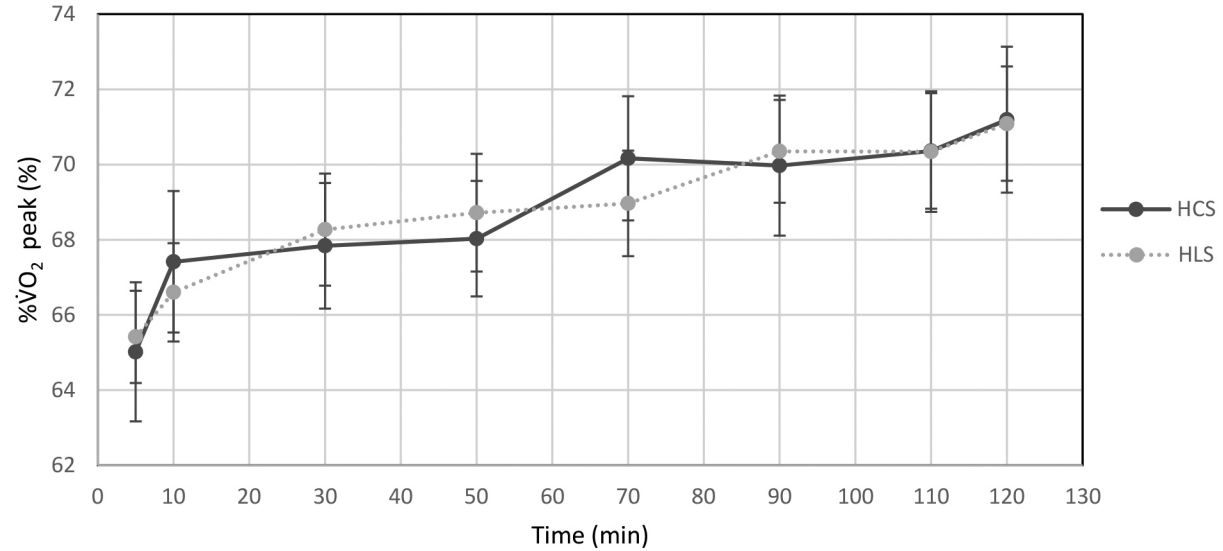

A

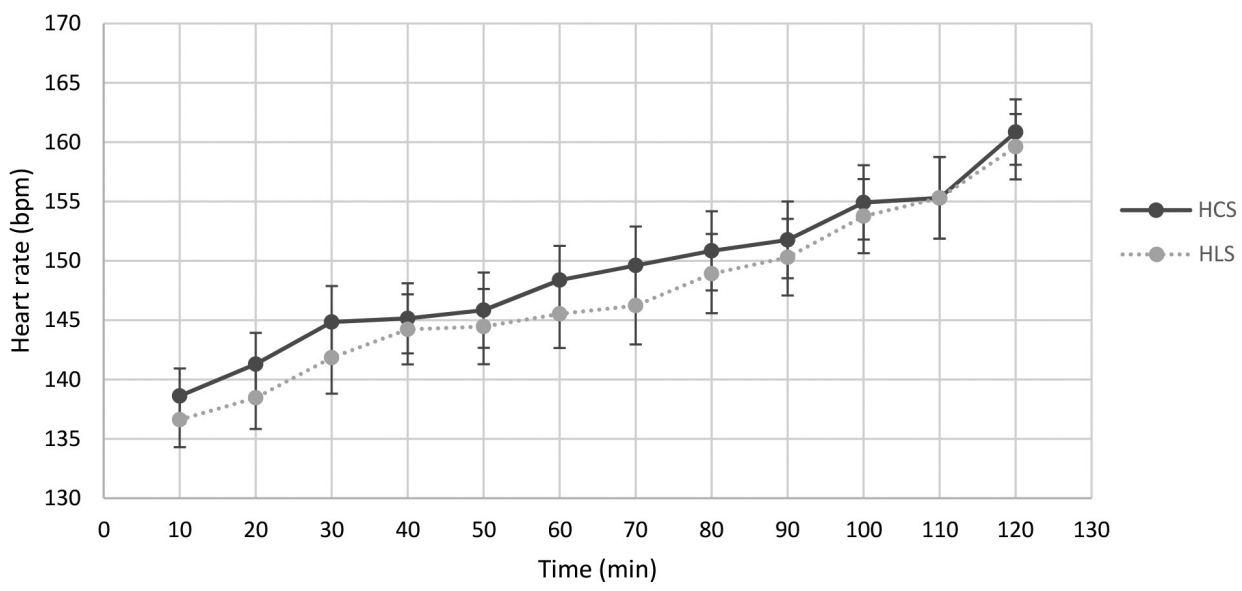

B
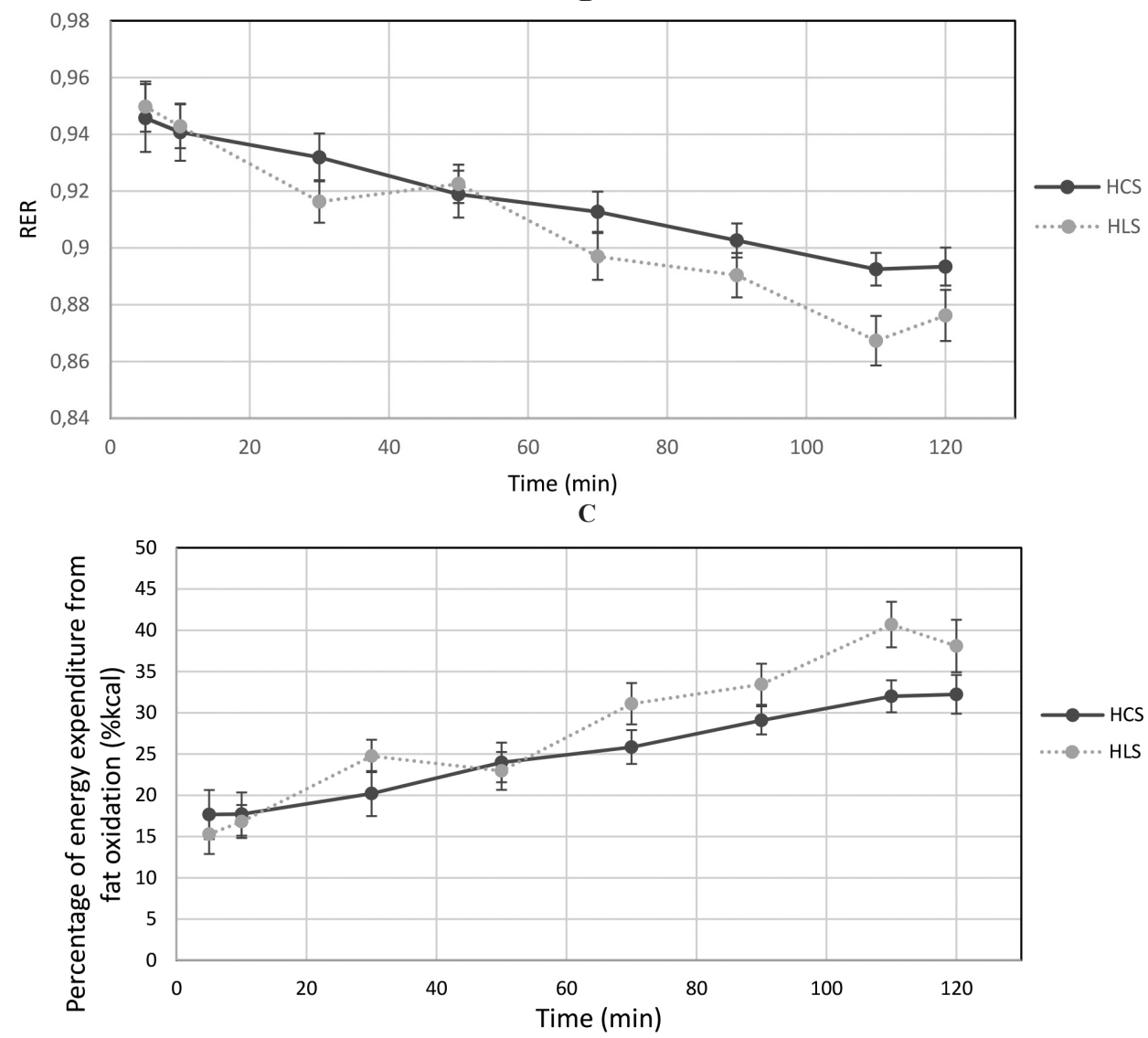

D 
and the HFS conditions decreased in a significant manner during the cycling effort. Furthermore, the analysis of variance showed that the RER slope for HFS decreased significatively more steeply.

The perceived exertion was measured using Borg's modified scale (1-10). The mean RPE during the SE with the HCS was lower compared to the HFS (3.62. \pm 0.6 vs $4.2 \pm 0.6 ; p=0.04)$. The RPE at the end of the SE (120 th minute) was also lower with the HCS $(5.0 \pm 1.5$ vs $5.9 \pm 1.4 ; p=0.04)$. As shown in fig.1. D, the percentage of energy expenditure from the oxidation of fat increased during the SE. As shown in table 5-3, in the second hour, the mean rate of fat oxidation was significantly lower with the HCS $\left(0.53 \pm 0.17\right.$ vs $\left.0.62 \pm 0.14 \mathrm{~g} \cdot \mathrm{min}^{-1} ; p=0.04\right)$. Also, the highest fat oxidation rate during the cycling effort was lower with the HCS compared to the HFS and the difference was significant $(0.63 \pm 0.19$ vs $0.73 \pm$ $\left.0.16 \mathrm{~g} \cdot \mathrm{min}^{-1} ; p=0.008\right)$. The order of effect was measured, and it was not significant, so the order of the experimentations did not affect the results.

\section{3-minute time trial}

The mean power for the TT was significantly $(p<0.05)$ higher with HCS compared to HFS $(347.0 \pm 77.4$ watts $326.5 \pm 88.8 \mathrm{~W})$. The mean heart rate for the TT was higher when compared to HFS $(178.5 \pm 7.7$ vs $174.8 \pm 7.4 \mathrm{bpm} ; p<0.01)$ and the RER was also higher with HCS compared to HFS $(1.07 \pm 0.06$ vs $1.02 \pm 0.02 ; p<0.01)$.
Table 3. Power, perceived exertion ratings, metabolic values and gross efficiency during cycling effort
PE: perceived exertion;

RER: Respiratory exchange ratio; SE: steady effort;

TSI \%: Tissue saturation index;

TT: time trial

$\mathrm{N}=13$

$* p<0.05$

$\dagger p<0.01$

\begin{tabular}{|c|c|c|}
\hline & HCS & HFS \\
\hline Mean Watts TT & $347.0 \pm 77.4^{*}$ & $326.5 \pm 88.8$ \\
\hline Mean HR TT & $178.5 \pm 7.7 \dagger$ & $174.8 \pm 7.4$ \\
\hline Mean HR SE & $147.5 \pm 9.7$ & $145.0 \pm 7.4$ \\
\hline Mean $\dot{\mathrm{VO}}_{2} \mathrm{TT}\left(\mathrm{mlO}_{2} \cdot \mathrm{kg}^{-1} \cdot \mathrm{min}^{-1}\right)$ & $55.0 \pm 10.3$ & $53.4 \pm 10.1$ \\
\hline Mean $\% \dot{\mathrm{VO}}_{2}$ peak TT & $90.7 \pm 11.2$ & $85.3 \pm 11.7$ \\
\hline Mean $\dot{\mathrm{VO}}_{2} \mathrm{SE}\left(\mathrm{mlO}_{2} \cdot \mathrm{kg}^{-1} \cdot \mathrm{min}^{-1}\right)$ & $41.4 \pm 6.0$ & $40.9 \pm 5.1$ \\
\hline$\% \dot{\mathrm{VO}}_{2}$ peak SE & $68.5 \pm 6.0$ & $67.7 \pm 3.8$ \\
\hline Mean RER TT & $1.07 \pm 0.06 \dagger$ & $1.02 \pm 0.02$ \\
\hline Mean RER SE & $0.92 \pm 0.02$ & $0.87 \pm 0.08$ \\
\hline Mean PE (modified Borg scale 0 to 10 ) SE & $3.6 \pm 0.6^{*}$ & $4.2 \pm 0.6$ \\
\hline PE (modified Borg scale 0 to 10 ) at $120^{\text {th }}$ minute & $5.0 \pm 1.5^{*}$ & $5.9 \pm 1.4$ \\
\hline Mean fat oxidation SE $\left(\mathrm{g} \cdot \mathrm{min}^{-1}\right)$ & $0.44 \pm 0.17$ & $0.48 \pm 0.11$ \\
\hline Mean fat oxidation during $1^{\text {st }}$ hour of $\mathrm{SE}\left(\mathrm{g} \cdot \mathrm{min}^{-1}\right)$ & $0.35 \pm 0.19$ & $0.34 \pm 0.11$ \\
\hline Mean fat oxidation during $2^{\text {nd }}$ hour of SE $\left(\mathrm{g} \cdot \mathrm{min}^{-1}\right)$ & $0.53 \pm 0.17 *$ & $0.61 \pm 0.14$ \\
\hline Maximum fat oxidation during SE $\left(\mathrm{g} \cdot \mathrm{min}^{-1}\right)$ & $0.63 \pm 019 \dagger$ & $0.73 \pm 0.16$ \\
\hline Gross efficiency (\%) during $2 \mathrm{~h}$ steady effort & $19.98 \pm 2.01$ & $19.43 \pm 1.50$ \\
\hline
\end{tabular}

\section{Muscle oxygenation values during the cycling efforts}

The muscle oxygenation values measured by NIRS during the cycling efforts are displayed in table 5-4. There were no significant differences between HCS and HFS. As shown in fig. 2, $\triangle \mathrm{HHb}$ increased rapidly during the TT and $\Delta \mathrm{HHb} / \mathrm{V}_{2}$ decreased during the TT for both HCS and HFS.
Table 4. Muscle oxygenation values during the cycling efforts

$\mathrm{HHb}$ : deoxyhemoglobin; THb: Total hemoglobin; TSI \%: Tissue saturation index; Hbdiff: Hb difference; SE: Steady effort;

TT: Time trial

$\mathrm{N}=13$

$* \mathrm{p}<0.05$

$\uparrow \mathrm{p}<0.01$

\begin{tabular}{|l|c|c|}
\hline \multicolumn{1}{|c|}{ Muscle oxygenation values } & HCS & HFS \\
\hline Mean $\Delta$ HHb TT & $38.7 \pm 28.8$ & $32.5 \pm 19.0$ \\
\hline Max $\Delta$ HHb TT & $40.5 \pm 32.5$ & $32.9 \pm 19.0$ \\
\hline Mean $\Delta$ HHb SE & $26.0 \pm 12.2$ & $27.3 \pm 18.8$ \\
\hline Mean \% HHb TT & $153.1 \pm 55.0$ & $142.1 \pm 35.8$ \\
\hline Max \% HHb TT & $173.7 \pm 72.2$ & $144.2 \pm 35.8$ \\
\hline Mean \% HHb SE & $115.5 \pm 33.4$ & $116.7 \pm 23.1$ \\
\hline Mean TSI \% TT & $33.0 \pm 16.7$ & $38.1 \pm 14.9$ \\
\hline Mean TSI \% SE & $39.6 \pm 14.0$ & $42.5 \pm 14.3$ \\
\hline Mean $\Delta$ THb TT & $32.2 \pm 41.4$ & $20.1 \pm 8.9$ \\
\hline Mean $\Delta$ THb SE & $25.5 \pm 36.0$ & $16.6 \pm 9.2$ \\
\hline Mean $\Delta$ Hbdiff SE & $-39.0 \pm 21.6$ & $-38.8 \pm 33.3$ \\
\hline Mean $\Delta$ Hbdiff TT & $-60.3 \pm 49.8$ & $-46.0 \pm 34.3$ \\
\hline
\end{tabular}


Figure 2. (A), $\Delta \mathbf{H H b}$ and (B), $\Delta \mathrm{HHb} / \dot{\mathrm{VO}}_{2}$ during the cycling efforts when consuming either carbohydrates or lipids

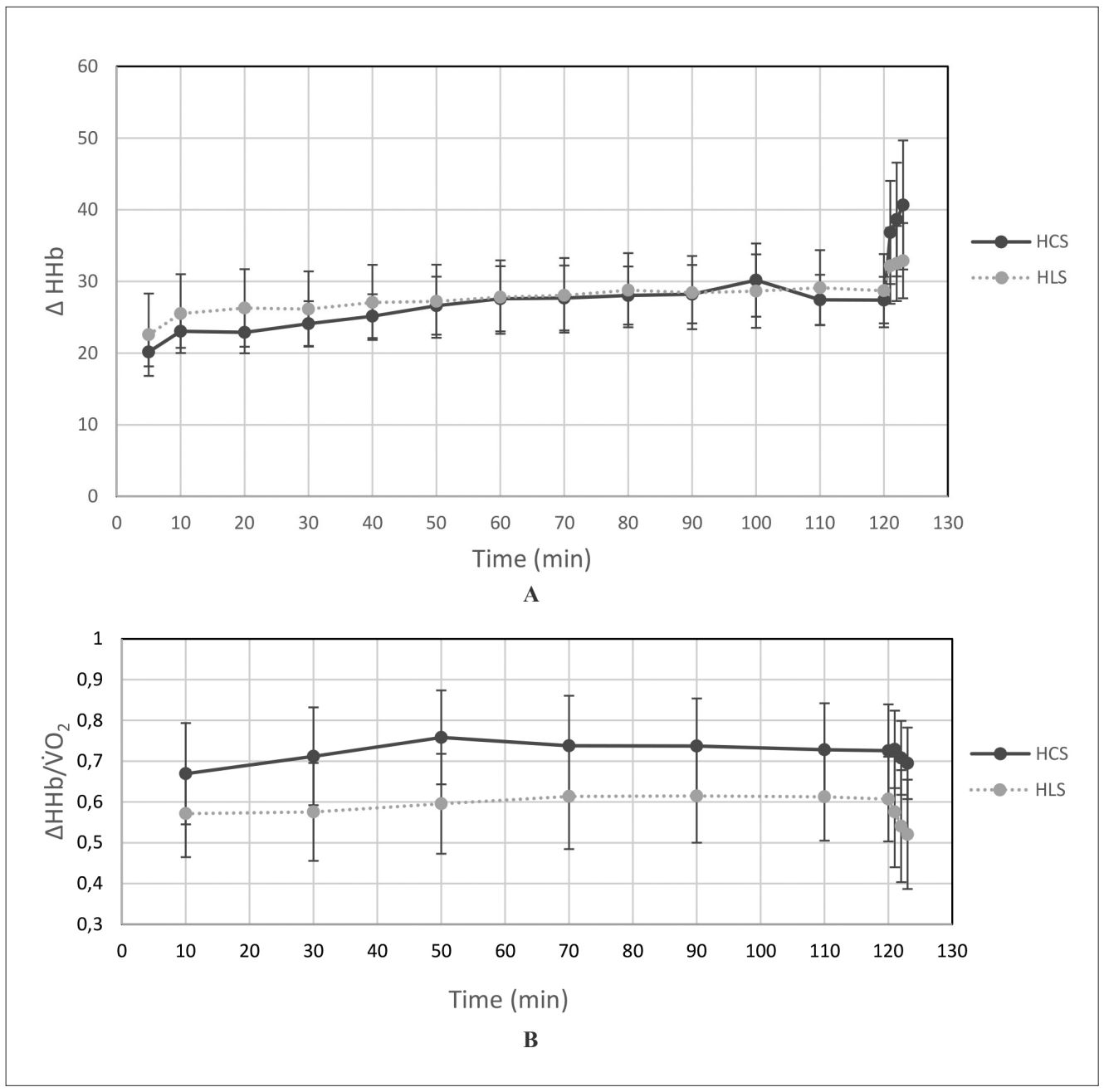

\section{DISCUSSION}

The objective of this study was to determine the effects of consuming a high fat solution compared to a high carbohydrate solution (HCS) during a cycling effort on the oxidation of energetic substrates, on muscle oxygenation and on performance with cyclists and triathletes. We hypothesized that the deoxyhemoglobin $(\mathrm{HHb})$ would be higher during the SE when the participants consume the high fat solution since more oxygen would be used in the muscles, due to a higher fat oxidation rate, but we did not observe a significant effect of the acute consumption of the HFS compared to the HCS on muscle oxygenation during the cycling effort. We also hypothesized that the fat oxidation would be higher when the subjects are consuming a HFS compared to a HCS. Even though the mean rate of fat oxidation for the SE was not significantly different, we did observe a significantly higher rate of fat oxidation for the last hour of the SE effort with the HFS. We also hypothesized that the rate of perceived exertion (RPE) would be significantly higher when the participants consume the HFS compared to the HCS and that the performance during the time-trial would be negatively affected when the participants consume the HFS. We did observe a negative impact of the HFS on both performance and rating of perceived exertion.

\section{Effect of the substrates consumed on metabolic values and fat oxidation}

We have observed that the percentage of calories from the oxidation of fat increased during the SE for both the HCS and the HFS and that the mean rate of fat oxidation in the second hour was significantly higher with the HFS compared to the HCS. Many studies have observed a higher fat oxidation rate with the ingestion or intravenous injection of lipids during a physical effort. (Costill et al., 1977; Hawley et al., 2000; Vukovich et al., 1993). However, since we did not compare the HFS 
and HCS conditions with a control condition where the participants would have consumed nothing during the exercise, it is not possible to know with certainty if the higher fat oxidation rate with HFS is mainly due to the consumption of lipids or to the fact that the participants did not consume carbohydrates. Furthermore, since we did not use isotopically labelled solutions, it is not possible to know how much of the HFS that was ingested was oxidized. It could be possible that only a marginal portion of the HFS was absorbed and oxidized during the exercise. However, based on the literature, it is expected that a significant quantity of the HFS was oxidized in addition to the oxidation of endogenous lipid sources (intramuscular triglycerides and adipose tissue) and that if we had compared the rate of fat oxidation with a control group, the rate of fat oxidation would have been higher for HFS compared to the control group (Décombaz et al., 1983; Hawley, J. A., 2002; Massicotte et al., 1992; Satabin et al., 1987).

We also demonstrated that the RER slope for both the HCS and the HFS conditions decreased in a significant manner during the SE and the RER slope for HFS decreased more steeply, which shows a greater reliance on fat oxidation for energy (Miura et al., 2000). It is well known that as the duration of a steady physical effort increases, the fat oxidation rate also increases (Achten \& Jeukendrup, 2004; Purdom et al., 2018; Romijn et al., 1993; Van Hall, 2015).

\section{Economy of effort}

In endurance sport, having a good economy of effort is important, since less energy is spent at a specific intensity. The economy of effort of an athlete is affected by many factors, such as metabolic, biomechanical, neuromuscular and cardiorespiratory factors. The economy of effort can also be affected by the diet of the individual. This was observed in cyclists by Cole et al. (2014) and in elite race walkers by Burke et al. (2017). However, Shaw et al. (2019), have demonstrated that the economy of effort of runners was not affected at an intensity inferior to $60 \% \dot{\mathrm{VO}}_{2}$ max following 31 days of ketogenic diet, but the economy of effort was affected at an intensity superior to $70 \% \dot{\mathrm{VO}}_{2}$ max. In this present study, we studied the effect of the acute ingestion of a high fat solution instead of the chronic effect. We did not observe an increase in oxygen consumption during the SE or an effect on gross efficiency when the participants consumed the HFS.

\section{Performance and rate of perceived exertion}

The performance during the TT was better with the HCS compared to the HFS, which was expected since carbohydrate is known to have an ergogenic effect (Currel \& Jeukendrup, 2008; Karelis et al., 2010). Furthermore, the RPE was significantly higher when the participants consumed the HFS. The RPE affect greatly the central motor drive and therefore, mechanical output that is produced by an individual (Christian et al., 2014; Marcora \& Staiano, 2010). Therefore, the RPE at the end of SE may have affected the performance during the following TT. The fact that the perceived exertion was lower with the HCS compared to the HFS is in agreement with the literature. Many studies have observed a lower RPE with carbohydrate supplementation compared to a placebo (Coggan \& Coyle, 1987; Kang et al., 1996; Robertson et al., 1990; Utter et al., 2002; Utter et al., 2004). This reduced RPE can be partially explained by a greater carbohydrate oxidation rate in the carbohydrate supplementation group (Robertson et al., 1990; Utter et al., 2004) and by the effect of carbohydrate supplementation on the central nervous system (Beelen et al., 2009; Carter et al., 2004; Chambers et al., 2009).

\section{Gastrointestinal distress}

Of the 14 participants who began all the experimentations, one person was not able to finish the SE when he consumed the high fat mix due to GI distress and due to lack of energy. The individual had to stop after 88 minutes. This individual did not have any GI issue when he consumed the HCS. This participant was the only one who couldn't complete the cycling efforts, but another participant also had GI distress when consuming the HFS, which negatively impacted his perception of effort during the SE and his performance during the TT. The other participants had no GI discomfort with the HCS and the HFS. A few studies have observed that the consumption of MCT oil during exercise can result in GI distress (Gomes \& Aoki, 2014; Ivy et al., 1980; Lowery, 2004).

\section{Muscle oxygenation}

Muscle oxygenation in the vastus lateralis was measured with NIRS during both the preliminary test and the two experimentations. According to the literature, during the incremental test, in most of the participants, deoxyhemoglobin $(\Delta \mathrm{HHb})$ increased as 
the intensity increased until a breakpoint and from that point, $\triangle \mathrm{HHb}$ increased at a less steep slope (Azevedo et al., 2020; Ferreira et al., 2007; Murias et al., 2013; Spencer et al., 2012). However, in 3 of the 15 participants $\triangle \mathrm{HHb}$ increased linearly during the test until the end of the test. These 3 participants were amongst the fittest athletes in the group of participants $\left(61.32-69.52 \mathrm{mlO}_{2} \cdot \mathrm{kg}^{-1} \cdot \mathrm{min}^{-1}\right)$. This was also observed by Gendron et al. (2018). This could be explained by a higher oxidative capacity in these participants due to a higher proportion of slow twitch fibers and/or to mitochondrial adaptations such as a higher density and volume of mitochondria and enhanced mitochondrial activity, as well as greater capillary density (Boone et al., 2009; Trappe et al., 2006). A higher proportion of slow twitch fibers would delay the recruitment of fast twitch fibers, which have better fractional $\mathrm{O}_{2}$ extraction capacity than slow twitch fibers (Behnke et al., 2003; Boone et al., 2009; McDonough et al., 2005; Ferreira et al., 2006).

Furthermore, in most of the participants, the ratio between the deoxygenation in the vastus lateralis and the pulmonary oxygen consumption $\left(\Delta \mathrm{HHb} / \dot{\mathrm{V}}_{2}\right)$ increased until a maximal value and then decreased before the $\dot{\mathrm{V}}_{2}$ peak, which shows that at a high intensity, oxygenation in the vastus lateralis plateaued while systemic $\dot{\mathrm{VO}}_{2}$ increased due to an increase in oxygen consumption in other muscles such as the respiratory muscles and possibly also the arms, since there is usually more upper body movement at the end of an incremental test (Gendron et al., 2018). However, in two of the fittest participants, $\Delta \mathrm{HHb} / \mathrm{V}_{2}$ increased until the $\dot{\mathrm{V}} \mathrm{O}_{2}$ peak, which was also observed by Gendron et al. (2018). We observed a significant correlation between the intensity $\left(\dot{\mathrm{VO}}_{2}\right.$ peak) corresponding to the $\max \Delta \mathrm{HHb} / \mathrm{VO}_{2}$ and the $\mathrm{Fat}_{\text {max }}$ intensity. Therefore, the participants with a higher max $\Delta \mathrm{HHb} / \dot{\mathrm{VO}}_{2}$ intensity tended to also have a higher Fat $_{\max }$ intensity. This shows, as demonstrated by Zurbuchen et al. (2020), that the fat oxidation capacity is related to the muscle deoxygenation capacity.

Because of the increased cost in oxygen for ATP regeneration with fat oxidation compared with carbohydrates oxidation (Burke et al., 2017; Jeukendrup \& Wallis, 2004; Welch et al., 2007), we hypothesized that during the SE, more oxygen would have been required with HFS, so $\triangle \mathrm{HHb}$ would have been higher. The ratio of ATP regenerated by molecule of oxygen consumed by the mitochondria is known as the $\mathrm{P} / \mathrm{O}$ ratio (Befroy et al., 2008; Brand, 2005; Salin et al., 2015). Based on theoretical and empirical data, the $\mathrm{P} / \mathrm{O}$ ratio for the oxidation of glucose is $\sim 15 \%$ compared to the ratio for the oxidation of a fatty acid (Brand, 2005; Welch et al., 2007). However, we were not able to observe significant differences between the HCS and the HFS for the muscle oxygenation during the cycling efforts.

We observed during the TT that the $\triangle \mathrm{HHb}$ tended to be higher during the HCS compared to HFS, but it was not significant. This can be explained by the fact that the participants generated more power output during the TT with the HCS. Furthermore, $\triangle \mathrm{HHb}$ increased significantly during the TT that followed the SE for both HCS and HFS. When the intensity is higher, more oxygen is consumed by the muscles, so $\mathrm{HHb}$ increases and $\mathrm{HbO}_{2}$ decreases (Christmass et al., 1999; Grassi et al., 1999, Kawaguchi et al., 2001).

\section{Fat $_{\max }$ and the maximal fat oxidation}

During a test $\mathrm{Fat}_{\max }$, the quantity of fat oxidized in absolute terms $\left(\mathrm{g} \cdot \mathrm{min}^{-1}\right)$ increases as the intensity increases until it reaches its maximum value at sub-maximal intensity, which is named maximal fat oxidation (MFO) and the corresponding intensity is named the Fat ${ }_{\max }$ intensity (Achten et al., 2002; Nordby et al., 2006). As the intensity increases pass the $\mathrm{Fat}_{\max }$ intensity, the absolute oxidation of fat decreases until it is almost null at a really high intensity. In the present study, the relative Fat $_{\text {max }}$ intensity was $51.1 \pm 11.2 \% \dot{\mathrm{VO}}_{2}$ peak and it is usually situated between 45 and $65 \%$ of $\dot{\mathrm{V}}_{2}$ peak (Achten \& Jeukendrup, 2004; Venables et al., 2005). In the present study, the mean MFO was considerably higher than the MFO obtained in most studies (Nordby et al., 2006; Randell et al., 2016; Robinson et al., 2015; Stisen et al., 2006; Venables et al., 2005). The fact that most participants competed in half Ironman triathlons and that some participants even participated in Ironman triathlon, which are ultra-endurance events, may explain the higher MFO values obtained in this study. However, no participants followed, or has ever followed a low carb high fat diet, so the high MFO values can unlikely be explained by the diet of the participants. 


\section{Limitations}

This study has some limitations. First of all, we did not include a familiarization session to allow the participants to get familiarized to the time trial test. The participants could have cycled for one hour at $65 \%$ of MAP and then done a 3-minute time trial in order to learn how to pace a short time-trial. In order to determine if the lack of a familiarization session affected the results, we measured the order of effect and it was not significant. Therefore, since the order of the experimentations did not affect the results, it is unlikely that the lack of a familiarization session had an impact on the results. Furthermore, we did not include a control group where the participants did not consume food during the experiments. Even though some studies studying the effects of the ingestion of MCT have included a control group of no food intake (Angus et al., 2000; Jeukendrup et al., 1998; Massicotte et al., 1992), many studies have not included a control group of no food intake (Decombaz et al., 1983; Goedecke et al., 1999; Horowitz et al., 2000; Ivy et al., 1980; Jeukendrup et al., 1995; Jeukendrup et al., 1996; Satabin et al., 1987; Van Zeyl et al., 1996; Vistisen et al., 2003). That would have allowed to determine if the ingestion of fat increased the fat oxidation rate compared to no food intake and if the time trial performance was improved with the HFS compared to no food intake. Furthermore, it would have allowed us to determine if the RPE is higher without any food intake compared to with the HFS. If that would have been the case, we could have concluded that even though the RPE is higher with the HFS compared to the HCS, the ingestion of lipids is beneficial compared to no food intake because it would have reduced the RPE.

Another limitation of the study is that the quantity of HCS and HFS were not administered based on the weight of the participants. Instead, since all the participants were male athletes and since the difference in weight was minimal $(74,9 \pm$ $6,5 \mathrm{~kg}$ ), we administered the same quantity of HCS and HFS to all the participants, based on the recommendations of ingestion between 60 and $90 \mathrm{~g}$ of carbohydrate per hour during exercise of length superior or equal to 2 hours (Burke \& Hawley, 2018; Stellingwerff \& Cox, 2014). Furthermore, even though both the HCS and the HFS were supposed to be indistinguishable (both solutions tasted like chocolate and were administered in an opaque flask), the HFS was easily distinguishable because the participants could identify the taste of nuts. Finally, we did not used isotopically traced solutions, so it is not possible to determine what quantity of the HFS ingested that was oxidized. However, many studies have observed that the lipids ingested were partly oxidized, both at rest (Metges et al., 1991) and during exercise (Décombaz et al., 1983; Jeukendrup et al., 1995; Massicotte et al., 1992; Satabin et al., 1987). We can therefore estimate that part of the lipids in the HFS were indeed oxidized during the experiment.

\section{CONCLUSION}

In summary, we have shown that the acute consumption of a HFS increased the rate of fat oxidation at the end of a long constant effort. Therefore, without following a low carb high fat diet, it is possible to acutely increase the rate of fat oxidation for a specific submaximal endurance training. However, we have also shown that the acute consumption of a HFS negatively affected both the performance during a TT after a long constant effort and the RPE. We did not, however, observe a significant effect of the acute consumption of the HFS compared to the HCS on muscle oxygenation during the cycling efforts. Finally, we have shown that cyclists who demonstrated a high skeletal muscle deoxygenation relative to their pulmonary oxygen consumption $\left(\Delta \mathrm{HHb} / \dot{\mathrm{V}}_{2}\right)$ had a higher fat oxidation capacity (higher Fat max $_{\text {ax }}$ ), which shows that the fat oxidation capacity is to a certain degree related to the muscle oxygenation capacity. In this present study we looked at the effect of the acute consumption of a HFS on muscle oxygenation, performance and on the oxidation of substrates, but it would be interesting to determine if consuming a HFS during multiple training sessions over a prolonged period of time can have an effect on muscle oxygenation during a long cycling effort and a more pronounced effect performance, and on the oxidation of substrates.

\section{Competing interests}

The authors declare there are no competing interests.

\section{Funding}

The authors declare there is no specific funding for this work. 


\section{REFERENCES}

Achten, J., Gleeson, M. and Jeukendrup, A.E. (2002). Determination of the exercise intensity that elicits maximal fat oxidation. Medicine and Science in Sports and Exercise, 34, 92-97.

Achten, J., Jeukendrup, A. E. (2003). Maximal fat oxidation during exercise in trained men. International Journal of Sports Medicine, 24, 603-608.

Achten, J., Jeukendrup, A. E. (2004). Optimizing fat oxidation through exercise and nutrition. Nutrition, 20(78), 716-727. https://doi.org/10.1016/j.nut.2004.04.005

Angus, D. J., Hargreaves, M., Dancey, J., Febbraio, M. A. (2000). Effect of carbohydrate or carbohydrate plus medium-chain triglyceride ingestion on cycling time trial performance. Journal of Applied Physiology, 88(113).

Azevedo, R., A., Saona, J. E. B., Inglis, E. C., Iannetta, D., Murias, J. M. (2020). The effect of the fraction of inspired oxygen on the NIRS-derived deoxygenated hemoglobin "breakpoint" during ramp-incremental test. American Journal of Physiology- Regulatory, Integrative and Comparative Physiology, 318, 399-409. https://doi. org/10.1152/ajpregu.00291.2019

Baum, O., Gübeli, J., Frese, S., Torchetti, E., Malik, C., Odriozola, A., Graber, F., Hoppeler, H., Tschanz, S. A. (2015). Angiogenesis-related ultrastructural changes to capillariesinhuman skeletalmuscleinresponse to endurance exercise. Journal of Applied Physiology, 119, 1118-1126. https://doi.org/10.1152/japplphysiol.00594.2015

Beelen, M., Berguis, J., Bonaparte, B., Ballak, S. B., Jeukendrup, A. W., Van Loon, L. J. C. (2009). Carbohydrate Mouth Rinsing in the Fed State: Lack of Enhancement of Time-Trial Performance. International Journal of Sport Nutrition and Exercise Metabolism, 19, 400-409.

Befroy, D. E., Petersen, K. F., Dufour, S., Mason, G. F., Rothman, D. L. Shulman, G. I. (2008). Increased substrate oxidation and mitochondrial uncoupling in skeletal muscle of endurance-trained individuals. The National Academy of Sciences of the USA, 105(43). https://doi.org/10.1073/pnas.0808889105

Behnke, B. J., McDonough, P., Padilla, D. J., Musch, T. I., Poole, D. C. (2003). Oxygen exchange profile in rat muscle of contrasting fibre types. Journal of Physiology, 549, 597-605. https://doi.org/10.1113/ jphysiol.2002.035915

Bhambhani, Y. N. (2004). Muscle oxygenation trends during dynamic exercise measured by near infrared spectroscopy. Canadian Journal of Applied Physiology, 29(4), 504-523.

Binzoni, T., Colier, W., Hiltbrand E., Hoofd, L., Cerretelli, P. (1999). Muscle $\mathrm{O}_{2}$ consumption by NIRS: a theoretical model. The American Physiological Society.

Bloor, C. M. (2005). Angiogenesis during exercise and training. Angiogenesis, 8, 263-271. https://doi. org/10.1007/s10456-005-9013-x.

Boone, J., Koppo, K., Barstow, T. J., Bouckaert, J. (2009). Pattern of deoxy[Hb $+\mathrm{Mb}]$ during ramp cycle exercise: influence of aerobic fitness status. European Journal of Applied Physiology, 105, 851-859. https:// doi.org/10.1007/s00421-008-0969-2

Boone, J., Koppo, K., Barstow, T. J., Bouckaert, J. (2010). Effect of exercise protocol on deoxy[Hb $+\mathrm{Mb}]$ : incremental step versus ramp exercise. Medecine \& Science in Sports \& Exercise, 42(5), 935-942. https://doi. org/10.1249/MSS.0b013e3181c0ecea

Bossi, A. H., Timmerman, W. P., Hopker, J. G. (2019). Energy expenditure equation choice: effects on cycling efficiency and its reliability. International Journal of Sports Physiology and Performance, https://doi. org/10.1123/ijspp.2018-0818.

Brand, M. D. (2005). The efficiency and plasticity of mitochondrial energy transduction. Biochemical Society Transactions, 33(5).

Bringard, A., Perrey, S. (2004). Influence of repeated isometric contractions on muscle deoxygenation and pulmonary oxygen uptake kinetics in humans. Clinical physiology and functional imaging, 24(4), 229-236.

Burke, L. M. (2010). Fueling strategies to optimize performance: training high or training low? Scandinavian Journal of Medicine \& Science in Sports, 20(2), 48-58. https://doi.org/10.1111/j.1600-0838.2010.01185.x

Burke, L. M., Hawler, J. A. (2018). Swifter, higher, stronger: what's on the menu? Science, 362, 781-787.

Burke, L. M., Ross, M. L., Garvican-Lewis, L. A., Welvaert, M., Heikura, I. A., Forbes, S. G., Mirstschin, J. G., Cato, L. E., Strobel, N., Sharma, A. P., Hawley, J. A. (2017). Low carbohydrate, high fat diet impairs exercise economy and negates the performance benefit from intensified training in elite race walkers. Journal of Physiology, 595(9), 2785-2807. https://doi.org/10.1113/JP273230

Carter, J. M., Jeukendrup, A E., Jones, D. A. (2004). The effect of carbohydrate mouth rinse on 1-h cycle time trial performance. Physical Fitness and Performance, 36(12), 2107-2111. https://doi.org/10.1249/01. MSS.0000147585.65709.6F

Celi, B., Boone, J., Van Coster, R., Bourgois, J. (2012). Reliability of near infrared spectroscopy (NIRS) for measuring forearm oxygenation during incremental handgrip exercise. European Journal of Applied Physiology, 112, 2369-2374. https://doi.org/10.1007/ s00421-011-2183-x

Chambers, E. S., Bridge, M. W., Jones, D. A. (2009). Carbohydrate sensing in the human mouth: effects on exercise performance and brain activity. Journal of physiology, 587(8), 1779-1793. https://doi.org/10.1113/ jphysiol.2008.164285

Christian, R. J., Bishop, D. J., Billaut, F., Girard, O. (2014). The role of sense of effort on self-selected cycling power output. Frontiers in Physiology, 5(115), 1-10. https://doi.org/10.3389/fphys.2014.00115.

Christmass, M. A., Dawson, B., Passeretto, P., Arthur, P. G. A. (1999). comparison of skeletal muscle oxygenation and fuel use in sustained continuous and 
intermittent exercise. European Journal of Applied Physiology, 80, 423-435.

Coggan, A. R., Coyle, E. F. (1987). Reversal of fatigue during prolonged exercise by carbohydrate infusion or ingestion. Journal of Applied Physiology, 63, 23882395.

Cole, M., Coleman, D., Hopker, J., Wiles, J. (2014) Improved gross efficiency during long duration submaximal cycling following a short-term high carbohydrate diet. International Journal of Sports Medicine, 35(3), 265-269.

Costill, D.L., Coyle, E., Dalsky, G., Evans, W., Fink, W., Hoopes, D. (1977). Effects of elevated plasma FFA and insulin on muscle glycogen usage during exercise. Journal of Applied Physiology, 43, 695-699.

Coyle, E. F. (1995). Integration of the physiological factors determining endurance performance ability. Exercise and Sport Sciences Review, 23, 25-64.

Coyle, E. F. (2005). Improved muscular efficiency displayed as Tour de France champion matures. Journal of Applied Physiology (1985), 98, 2191-2196.

Coyle, E. F., Coggan, A. R., Hemmert, M. K., Ivy, J. L. (1986). Muscle glycogen utilization during prolonged strenuous exercise when fed carbohydrate. Journal of Applied Physiology, 61, 165-172.

Coyle, E. F., Hagberg, J. M., Hurley, B. F., Martin, W. H., Ehsani, A. A., Holloszy, J. O. (1983). Carbohydrate feeding during prolonged strenuous exercise can delay fatigue. Journal of Applied Physiology. 55(1), 230-235. https://doi.org/10.1152/jappl.1983.55.1.230

Currell, K., Jeukendruo, A. E. (2008). Superior Endurance Performance with Ingestion of Multiple Transportable Carbohydrates. Medicine \& Science in Sports \& Exercise, https://doi.org/10.1249/mss.0b013e31815adf19

Davis, J. M., Bailey, S. P., Woods, J. A., Galiano, F. J., Hamilton, M. T., Bartoli, W. P. (1992). Effects of carbohydrate feedings on plasma free tryptophan and branched-chain amino-acids during prolonged cycling. European Journal of Applied Physiology, 65, 513-519.

Décombaz, J., Arnaud, M. J., Milon, H., Moesch, H., Philippossian, G., Thélin, A.L., Howald, H. (1983). Energy Metabolism of Medium-chain Triglycerides versus Carbohydrates during Exercise. European Journal of Applied Physiology, 52, 9-14.

Dill, D. B., Edwards, H. T., Talbott, J. H. (1932). Studies in muscular activity: VII. Factors limiting the capacity for work. The Journal of Physiology, 77, 49-54.

El-Sayed, M. S., Balmer, J. Rattu, A. J. M. (1997). Carbohydrate ingestion improves endurance performance during a $1 \mathrm{~h}$ simulated cycling time trial. Journal of Sports Sciences, 15(2), 223-230, https://doi. org/10.1080/026404197367506

Fadel, P. J., Keller, D. M., Watanabe, H., Raven, P. B., Thomas, G. D. (2004). Noninvasive assessment of sympathetic vasoconstriction in human and rodent skeletal muscle using near-infrared spectroscopy and Doppler ultrasound. Journal of Applied Physiology, 96, 13231330. https://doi.org/10.1152/japplphysiol.01041.2003

Ferrari, M., Binzoni, T., Quaresima, V. (1997). Oxidative metabolism in muscle. Philosophical Transactions of the Royal Society.

Ferrari, M., Culver, J. P., Hoshi, Y. Wabnitz, H. (2016). Clinical near-infrared spectroscopy and imaging. Journal of Biomedical Optics, 21(9). https://doi.org/10.1117/1. JBO.21.9.091301

Ferreira, L. F., Koga, S., Barstow, T. J. (2007). Dynamics of noninvasively estimated microvascular $\mathrm{O}_{2}$ extraction during ramp exercise. Journal of Applied Physiology (1985), 103, 1999-2004. https://doi.org/10.1152/ japplphysiol.01414.2006

Ferreira, L. F., Paul McDonough, P., Behnke, B. J., Musch, T. I., Poole, D. C. (2006). Blood flow and $\mathrm{O}_{2}$ extraction as a function of $\mathrm{O}_{2}$ uptake in muscles composed of different fiber types. Respiratory Physiology \& Neurobiology, 153, 237-249.

Frandsen, J., Vest, S. D., Larsen, S., Dela, F., Helge, J. W. (2017). Maximal fat oxidation is related to performance in an Ironman triathlon. International Journal of Sports \& Medicine, 38, 975-982. https://doi. org/10.1055/s-0043-117178

Gendron, P., Laurencelle, L., Trudeau, F., Lajoie, C. (2018). Deoxy[Hb+Mb] increases consistently up to peak oxygen consumption in elite cyclists. International Journal of Applied Sports Sciences, 30(1), 11-19. https:// doi.org/10.24985/ijass.2018.30.1.11

Goedecke, J. H., Elmer-English, R., Dennis, S. C., Schloss, I., Noakes, T. D., Lambert, E. V. (1999). Effects of medium chain triacylglycerol ingested with carbohydrate on metabolism and exercise performance. International Journal of Sports Nutrition, 9(35).

Gomes, R. V., Aoki, M. S. (2003). Does medium chain triglyceride play an ergogenic role in endurance exercise performance? The Revista Brasileira de Medicina do Esporte, 9(3), 162-168.

Gonzalez, J. T., Fuchs, C. J., Betts, J. A., Van Loon, L. J. C. (2016). Liver glycogen metabolism during and after prolonged endurance-type exercise. American Journal of Physiology-Endocrinology and Metabolism, 311, 543-553. https://doi.org/10.1152/ajpendo.00232.2016

Grassi, B., Pogliaghi, S., Rampichini, S., Quaresima, V., Ferrari, M., Marconi, C., Cerretelli, P. (2003). Muscle oxygenation and pulmonary gas exchange kinetics during cycling exercise on-transitions in humans. Journal of Applied Physiology, 95, 149-158. https://doi. org/10.1152/japplphysiol.00695.2002

Hadzipetros, P. (2009). Triathlon: multi-event sport surges in popularity. CBC news. https://www.cbc.ca/ news/technology/triathlon-multi-event-sport-surges-inpopularity-1.799609.

Hall, U. A., Edin, F., Pedersen, A., Madsen, K. (2016). Whole-body fat oxidation increases more by prior exercise than overnight fasting in elite endurance athletes. Applied Physiology Nutrition and Metabolism, 41, 430-437. https://doi.org/10.1139/apnm-2015-0452

Havemann, L., West, S. J., Goedecke, J. H., Macdonald, I. A., St Clair Gibson, A., Noakes, T. D., Lambert, E. V. (2006). Fat adaptation followed by carbohydrate loading compromises high-intensity 
sprint performance. Journal of Applied Physiology, 100, 194-202.

Hawley, J. A. (2002). Effect of increased fat availability on metabolism and exercise capacity. Medicine \& Science in Sports \& Exercise, 1485-1491. https://sites.uni.edu/ dolgener/Advanced Sport Nutrition/Increased fat availability and exercise.pdf Accessed 8 November 2021

Hawley, J. A. (2014). Manipulating carbohydrate availability to promote training adaptations. Sports Science Exchange, 27(134), 1-7.

Hawley, J. A., Burke, L.M., Angus, D. J., Fallon, K. E., Martin, D. T., Febbraio, M. A. (2000). Effect of altering substrate availability on metabolism and performance during intense performance. British Journal of Nutrition, 84, 829-838.

Helge, J. W., Rehrer, N. J., Pilegaard, H., Manning, P., Lucas, S. J. E., Gerrard, D. F., Cotter, J. D. (2007). Increased fat oxidation and regulation of metabolic genes with ultraendurance exercise. Acta Physiologica. https://doi.org/10.1111/j.1748-1716.2007.01709.x

Hopker, J., Passfield, L., Coleman, D., Jobson, S., Edwards, L., Carter, H. (2009). The effects of training on gross efficiency in cycling: a review. International Journal of Sports Medicine, 30(12), 845-850. https:// doi.org/10.1055/s-0029-1237712

Horowitz, J. F., Mora-Rodriguez, R., Byerley, L. O. Coyle, E. F. (2000). Preexercise medium- chain triglyceride ingestion does not alter muscle glycogen use during exercise. Journal of Applied Physiology, 88(219).

Horowitz, J. F, Sidossis, L. S, Coyle, E. F. (1994). High efficiency of type 1 muscle fibres improves performance. International Journal of Sports Medicine, 15, 152-157.

Ianetta, D., Qahtani, A., Maturana, F. M., Murias, J. M. The near-infrared spectroscopy-derived deoxygenated haemoglobin breaking-point is a repeatable measure that demarcates exercise intensity domains. Journal of Science and Medicine in Sports, 20, 873-877.

Ivy, J.L., Costill, D.L., Fink, W.J., Maglischo, E. (1980). Contribution of medium and long chain triglyceride intake to energy metabolism during prolonged exercise. International Journal of Sports Medicine, 1(15).

Jeffries, O., Evans, D. T., Waldron, M., Coussens, A., Patterson, S. D. (2019). Seven-day ischaemic preconditioning improves muscle efficiency during cycling. Journal of Sports Sciences, 37(24), 2798-2805, https://doi.org/10.1080/02640414.2019.1664537

Jensen, J., Rustad, P. I., Kolnes, A. J., and Lai, Y. C. (2011). The role of skeletal muscle glycogen breakdown for regulation of insulin sensitivity by exercise. Frontiers in Physiology, 2(112). https://doi.org/10.3389/ fphys.2011.00112

Jeukendrup, A.E. (2010). Carbohydrate and exercise performance: the role of mul- tiple transportable carbohydrates. Current Opinion in Clinical Nutrition Metabolic Care, 13, 452-457. https://doi.org/10.1097/ $\underline{\text { MCO.0b013e328339de9f }}$

Jeukendrup, A.E., Achten, J. (2001). Fatmax: A New Concept to Optimize Fat Oxidation During Exercise? European Journal of Sport Science, 1(5).
Jeukendrup,A.E.,Aldred, S. (2004). Fat supplementation, health and endurance performance. Nutrition, 20, 678688.

Jeukendrup, A. E., Craig, N. P., Hawler, J. A. (2000). The bioenergetics of world class cycling. Journal of Science and Medicine in Sports, 3(4), 414-433.

Jeukendrup, A. E., Saris, W. H. M., Schrauwen, P., Brouns, F., Wagenmakers, A. J. M. (1995). Metabolic availability of medium chain triglycerides co-ingested with carbohydrates during prolonged exercise. Journal of Applied Physiology, 79(3), 756-762.

Jeukendrup, A. E., Saris, W. H. M., Van Diesen, R., Brouns, F., Wagenmakers, A. J. M. (1996a). Effect of endogenous carbohydrate availability on oral mediumchain triglyc- eride oxidation during prolonged exercise. Journal of Applied Physiology, 80(949).

Jeukendrup,A.E., Thielen, J.J.H. C., Wagenmakers, A. J.M., Brouns, F., Saris, W. H. M. (1998). Effect of MCT and carbohydrate ingestion on substrate utilization and cycling performance. American Journal of Clinical Nutrition, 67(397).

Jeukendrup, A. E., Wallis, G. A. (2004). Measurement of substrate oxidation during exercise by means of gas exchange measurements. International Journal of Sports Medicine, 26(1), 28-37. https://doi. org $/ 10.1055 / \mathrm{s}-2004-830512$

Jones, S., Chiesa, S.T., Chatuverdi, N., Hughes, A. D. (2016). Recent developments in near-infrared spectroscopy (NIRS) for the assessment of local skeletal muscle microvascular function and capacity to utilize oxygen. Artery research, 16, 25-33.

Kang, J., Robertson, R. J., Goss, F. L. (1996). Effect of carbohydrate substrate availability on ratings of perceived exertion during prolonged exercise of moderate intensity. Perceptual and Motor Skills, 82, 495-506.

Karelis, A. D., Smith, J. E. W., Passe, D. H., Péronnet, F. (2010). Carbohydrate Administration and Exercise Performance. What Are the Potential Mechanisms Involved? Sports Medicine, 40 (9), 747-763.

Kawaguchi, K., Tabusadani, M., Sekikawa, Y., Hayashi, Y. et Onari, K. (2001). Do the kinetics of peripheral muscle oxygenation reflect systemic oxygen intake? European Journal of Applied Physiology, 84, 158-161.

Knaier, R., Infanger, D., Niemeyer, M., Cajochen, C., Schmidt-Trucksäss, A. (2019). In athletes, the diurnal variation in maximum oxygen uptake are more than twice as large as the day-to-day variation. Frontiers in Physiology. 10(219). https://doi.org/10.3389/ fphys.2019.00219

Lowery, L. M. (2004). Dietary fat and sport nutrition: a primer. Journal of Sports science and medicine, 3, 106-117.

Marcora, S. M., Staiano, W. (2010). The limit to exercise tolerance in humans: mind over muscle? European Journal of Applied Physiology, 109, 763-770. https:// doi.org/10.1007/s00421-010-1418-6.

McDonough, P., Behnke, B. J., Padilla, D. J., Musch, T. I., Poole, D. C. (2005). Control of microvascular oxygen 
pressures in rat muscles comprised of different fibre types. Journal of Physiology, 563, 903-913. https://doi. org/10.1113/jphysiol.2004.079533

Massicotte, D., Péronnet, F., Brisson, G. R., HillaireMarcel, C. (1992). Oxidation of exogenous medium-chain free fatty acids during prolonged exercise: comparison with glucose. The American Physiological Society.

Maunder, E., Kilding, A. E., Plews, D. J. (2018). Substrate metabolism during Ironman triathlon: different horses on the same course. Sports Medicine, 48, 2219-2226.

Maunder, E., Plews, D. J., Kilding, A. E. (2018). Contextualizing maximal fat oxidation during exercise: determinants and normative values. Frontiers in Physiology, 9(599). https://doi.org/10.3389/ fphys.2018.00599

Metges, C. C., Wolfram, G. (1991). Medium- and longchain triglycerides labeled with $13 \mathrm{C}$ : comparison of oxidation after oral or parenteral administration in humans. Journal of Nutrition, 121, 31-36.

Mitchell, G. Training Status and Not Aging Per Se, Determines the Speed of the $\dot{V} O 2$ Kinetics Response (Unpublished master's thesis, University of Calgary, Calgary, Canada). https://doi.org/10.11575/ PRISM/28502. Retrieved from http://hdl.handle. net/11023/4076.

Miura, A., Sato, H., Sato, H., Hipp, B. J. W., Fukuba, Y. (2000). The effect of glycogen depletion on the curvature constant parameter of the power- duration curve for cycle ergometry, Ergonomics, 43(1), 133-141, https:// doi.org/10.1080/001401300184693

Murias, J. M., Spencer, M. D., Kowalchuk, J. M., Paterson, D. H. (2011). Muscle deoxygenation to $\mathrm{VO}_{2}$ relationship differs in young subjects with varying $\tau \mathrm{VO}_{2}$. European Journal of Applied Physiology, 111, 31073118. https://doi.org/10.1007/s00421-011-1937-9

Murias, J. M., Spencer, M. D., Keir, D. A., Paterson, D. H. (2013). Systemic and vastus lateralis muscle blood flow and $\mathrm{O} 2$ extraction during ramp incremental cycle exercise. American Journal of Physiology-Regulatory, Integrative and Comparative Physiology, 304, 720-725. https://doi.org/10.1152/ajpregu.00016.2013

Murias, J. M., Kowalchuk, J. M., Paterson, D. M. (2011). Speeding of $\mathrm{VO}_{2}$ kinetics in response to endurancetraining in older and younger women. European Journal of Applied Physiology, 111, 235-243. https://doi. org/10.1007/s00421-010-1649-6

Noakes, T. N. (2001). Energy systems and running performance. In. Lore of Running ( $4^{\text {th }}$ edition, pp. 125). Human Kinetics.

Nordby, P., Saltin, B., Helge, J. W. (2006). Whole-body fat oxidation determined by graded exercise and indirect calorimetry: a role for muscle oxidative capacity? Scandinavian Journal of Medicine \& Science in Sports, 16, 209-214.

Olamei, N. (2009). Reactive hyperemia as endothelial function determinants using plethysmography methods. (Master thesis, Montreal University, Canada). Retrieved from https://papyrus.bib.umontreal.ca/xmlui/ handle/1866/2854
Péronnet, F., Massicotte, D. (1991). Table of nonprotein quotient: an update. Canadian Journal of Sport Sciences, 16(1), 23-29.

Purdom, T., Kravitz, L., Dokladny, K., Mermier, C. (2018). Understanding the factors that effect maximal fat oxidation. Journal of the International Society of Sports Nutrition, 15(3). https://doi.org/10.1186/s12970-0180207-1

Randell, R. K., Rollo, I., Roberts, T., Dalrymple, K. J., Jeukendrup, A. E., Carter, J. M. (2016). Maximal fat oxidation rates in an athletic population. Medicine \& Science in Sports \& Exercise, 113-140. https://doi. org/10.1249/MSS.0000000000001084

Rengel, A., Pérez, E., Piombo, G., Ricci, J., Servent, A., Tapia, M. S., Gilbert, O., Montet, D. (2015). Lipid Profile and Antioxidant Activity of Macadamia Nuts (Macadamia integrifolia) Cultivated in Venezuela. Natural Science, 7, 535-547. https://doi.org/10.4236/ ns.2015.712054

Robertson, J. R., Stanko, R. T., Goss, F. L., Spina, R. J., Reilly, J. J., Greenawalt, K. D. (1990). Blood glucose extraction as a mediator of perceived exertion during prolonged exercise. European Journal of Applied Physiology, 61, 100-105.

Robinson, S. L., Hattersley, J., Frost, G. S., Chambers, E. S., Wallis, G. A. (2015). Maximal fat oxidation during exercise is positively associated with 24-hour fat oxidation and insulin sensitivity in young, healthy men. Applied Physiology, 118, 1415-1422. https://doi.org/10.1152/japplphysiol.00058.2015

Romijn, J. A., Coyle, E. F., Hibbert, J., Wolfe, R. R. (1992). Comparison of indirect calorimetry and a new breath $13 \mathrm{C} / 12 \mathrm{C}$ method during strenuous exercise. American Journal of Physiology, 263, 64-71.

Romijn, J. A., Gastaldelli, A., Horowitz, J. F., Endert, E., Wolfe, R. R. (1993). Regulation of endogenous fat and carbohydrate metabolism in relation to exercise intensity and duration. American Journal of PhysiologyEndocrinology Metabolism, 265, 380-391. https://doi. org/10.1152/ajpendo.1993.265.3.E380

Ryan, T. E., Erickson, M. L., Brizendine, J. T., Young, H. J., McCully, K. K. (2012). Noninvasive evaluation of skeletal muscle mitochondrial capacity with near-infrared spectroscopy: correcting for blood volume changes. Journal of Applied Physiology, 113, 175-183. https://doi.org/10.1152/japplphysiol.00319.2012

Sahlin, K., Sallstedt, E. K., Bishop, D., Tonkonogi, M. (2008). Turning down lipid oxidation during heavy exercise-what is the mechanism? Journal of Physiology and Pharmacology, 59(Suppl. 7), 19-30.

Salin, K., Auer, S. K., Ret, B., Selman, C., Metcalfe, N. B. (2015). Variation in the link between oxygen consumption and ATP production, and its relevance for animal performance. Proceedings Royal Society Publishing B, 282. https://doi.org/10.1098/rspb.2015.1028

Satabin, P., Portero, P., Defer, G., Bricout, J. Guezennec, C. Y. (1987). Metabolic and hormonal responses to lipid and carbohydrate diets during exercise in man. Medicine and Science in Sports and Exercise, 19(3), 218-223. 
Shaw, D. M., Merien, F., Maunder, E. D., Dulson, D. K. (2019). Effect of a Ketogenic Diet on Submaximal Exercise Capacity and Efficiency in Runners. Medicine and Science in Sports and Exercise, 51(10), 2135-2146. https://doi.org/10.1249/mss.0000000000002008

Smale, W. (2016). Pedal power - the unstoppable growth of cycling. BBC news. https://www.bbc.com/ news/business-35101252.

Spencer, M. D., Murias, J. M., Grey, T. M., Paterson, D. H. (2012). Regulation of $\mathrm{V} \quad \mathrm{O}_{2}$ kinetics by $\mathrm{O}_{2}$ delivery: insights from acute hypoxia and heavy-intensity priming exercise in young men. Journal of Applied Physiology, 112, 1023-1032. https://doi.org/10.1152/ japplphysiol.01215.2011

Spencer, M. D., Murias, J. M., Paterson, D. H. (2012). Characterizing the profile of muscle deoxygenation during ramp incremental exercise in young men. European Journal of Applied Physiology, 112, 33493360. https://doi.org/10.1007/s00421-012-2323-y

Stebbins, C. L., Moore, J. L., Casazza, G. A. (2014). Effects of cadence on aerobic capacity following a prolonged, varied intensity cycling trial. Journal of Sports Science \& Medicine, 13(1), 144-119.

Stellingwerff, T., Cox, G. R. (2014). Systematic review: Carbohydrate supplementation on exercise performance or capacity of varying durations. Applied Physiology, Nutrition and Metabolism, 39, 998-1011. https://doi. org/10.1139/apnm-2014-0027

Stisen, A. B., Stougaard, O., Langfort, J., Helge, J. W., Sahlin, K., Madsen, K. (2006). Maximal fat oxidation rates in endurance trained and untrained women. European Journal of Applied Physiology, 98, 497-506. https://doi.org/10.1007/s00421-006-0290-x

Trappe, S., Harber, M., Creer, A., Gallagher, P., Slivka, D., Minchev, K., Whitsett, D. (2006). Single muscle fibre adaptations with marathon training. Journal of Applied Physiology, 101,721-727. https://doi.org/10.1152/ japplphysiol.01595.2005

Utter, A. C., Kang, J., Nieman, D. C., Dumke, C. L., Mcanulty, S. R. (2004). Carbohydrate Supplementation and Perceived Exertion during Prolonged Running. Psychobiology and
Behavioral Strategies, 36(6), 1036-1041. https://doi. org/10.1249/01.MSS.0000128164.19223.D9

Utter, A. C., Kang, J., Robertson, R. J., Nieman, D. C., Chaloupka, E., Suminski, R. R., Piccinni, C. R. (2002). Effect of carbohydrate ingestion on ratings of perceived exertion during a marathon. Medicine \& Science in Sports \& Exercise, 34(11), 1779-1784.

Van Hall, G. (2015). The Physiological Regulation of Skeletal Muscle Fatty Acid Supply and Oxidation During Moderate-Intensity Exercise. Sports Medicine, 45(1), 23-32. https://doi.org/10.1007/s40279-015-0394-8

Van Zeyl, C. G., Lambert, E. V., Hawley, J. A., Noakes, T. D., Dennis, S. C. (1996). Effects of mediumchain triglyceride ingestion on carbohydrate metabolism and cycling performance. Journal of Applied Physiology, 80(2217).

Venables, M. C., Achten, J., Jeukendrup, A. E. (2005). Determinants of fat oxidation during exercise in healthy men and women: a cross-sectional study. Journal of Applied Physiology, 98, 160-167.

Vistisen, B., Nybo, L., Xu, X., Hoy, C. E., Kiens, B. (2003). Minor amounts of plasma medium-chain fatty acids and no improved time trial performance after consuming lipids. Journal of Applied Physiology, 95(2434)

Vukovich, M. D., Costill, D. L., Hickey, M. S., Trappe, S. W., Cole, K. J., Fink, W.J. (1993). Effect of fat emulsion infusion and fat feeding on muscle glycogen utilisation during cycle exercise. Journal of Applied Physiology, 75, 1513-1518.

Zurbuchen, A., Lanzi, S., Voirol, L., Trindale, C. B., Gojanovic, B., Kayser, B., Bourdillon, N., Chenevière, X., Malatesta, D. (2020). Fat oxidation kinetics is related to muscle deoxygenation kinetics during exercise. Frontiers in physiology, 11(571), 1-10. https://doi.org/10.3389/ fphys.2020.00571

Welch, K. C., Altshuler, D. L., Suarez, R. K. (2007). Oxygen consumption rates in hovering hummingbirds reflect substrate-dependent differences in $\mathrm{P} / \mathrm{O}$ ratios: carbohydrate as a 'premium fuel'. The Journal of Experimental Biology, 210, 2146-2153. https://doi. org/10.1242/jeb.005389 